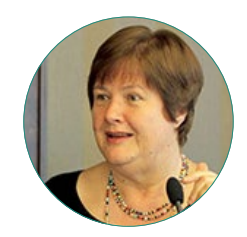

Н. Е. Тихонова

\title{
РЕСУРСООБЕСПЕЧЕННОСТЬ МАССОВЫХ СЛОЕВ НАСЕЛЕНИЯ СТРАНЫ: СОСТОЯНИЕ И ДИНАМИКА В 2008-2020 гГ.
}

\section{Правильная ссылка на статью:}

Тихонова Н.Е. Ресурсообеспеченность массовых слоев населения страны: состояние и динамика в 2008-2020 гг. // Мониторинг общественного мнения: экономические и социальные перемены. 2021. № 4. С. 121-138. https://doi.org/10.14515/monitoring.2021.4.1831. For citation:

Tikhonova N.E. (2021) Resourcefullness of the Mass Strata of Population: State and Dynamics in 2008-2020. Monitoring of Public Opinion: Economic and Social Changes. No. 4. P. 121-138. https://doi.org/10.14515/monitoring.2021.4.1831. (In Russ.) 
РЕСУРСООБЕСПЕЧЕННОСТЬ МАССОВЫХ СЛОЕВ НАСЕЛЕНИЯ СТРАНЫ: СОСТОЯНИЕ И ДИНАМИКА В 2008-2020 ГГ.

ТИХОНОВА Наталья Евгеньевна - доктор социологических наук, профессор, профессор-исследователь, главный научный сотрудник Института социальной политики, Национальный исследовательский университет «Высшая школа экономики", Москва, Россия E-MAIL: netichon@rambler.ru https://orcid.org/0000-0002-5826-4418

Аннотация. На материалах общероссийских исследований Института социологии ФНИСЦ РАН в статье показано, что обеспеченность россиян экономическим, квалификационным, властным и социальным ресурсами очень низка: четверть не обладает никакими из них, а треть - только одним. При этом ресурсообеспеченность постепенно уменьшается: за 20082020 гг. доля безресурсной группы выросла в относительном выражении почти на треть, а высокоресурсной сократилась на $21 \%$. Значительный вклад в это внес начавшийся под влиянием пандемии коронавирусной инфекции экономический кризис. Уменьшилось число имеющих сбережения и резко выросла доля имеющих кредитно-долговую нагрузку, структура которой за этот период ухудшилась. Одновременно сократились численность способных получить поддержку со стороны своего окружения в решении различных жизненных проблем и доля обладающих властным ресурсом, особенно в виде ресурса влияния у себя на работе. Что же касается квалификационного ресурса, то, хотя число людей с высшим образованием за это время значительно выросло, однако их дохо-
RESOURCEFULLNESS OF THE MASS STRATA OF POPULATION: STATE AND DYNAMICS IN 2008-2020

Natalia E. TIKHONOVA ${ }^{1}-$ Dr. Sci. (Soc.), Professor, Professor-Researcher; Principal Researcher at the Institute of Social Policy

E-MAIL: netichon@rambler.ru

https://orcid.org/0000-0002-5826-4418

\footnotetext{
${ }^{1}$ HSE University, Moscow, Russia
}

Abstract. Based on the data from allRussian surveys carried out by the Institute of Sociology of the FCTAS RAS, the paper shows that the level of economic, qualification, power and social resources among Russians is very low: a quarter of the population do not have any of them, and a third part have only one. The population resourcefulness is gradually decreasing - in 2008-2020, the share of the group with no resources increased in relative terms by almost one third, and the highly resourceful group decreased by $21 \%$. The last economic crisis caused by the pandemic significantly contributed to that. The share of those who have savings has decreased while the share of those have creditor-debitor burden has sharply increased accompanied by the deterioration of the group structure. In parallel, the number of individuals who are able to receive support from their social surroundings to cope with life problems have decreased and the same goes for those have power resources, especially potential to influence at work. As for the qualification resource, although the number of people with higher education has grown significantly during this time, their incomes have relatively dropped and the role of this resource 
ды относительно упали и роль этого ресурса в обеспечении благополучия россиян уменьшилась. Все это говорит о снизившемся под влиянием череды экономических кризисов разной природы "запасе прочности" населения страны. Судя по устойчивости этого тренда, он сохранится и в будущем. Для эволюции социальной структуры российского общества, с учетом приоритетов реализуемой социальной политики государства, это означает усиление тенденций, прослеживавшихся все последние годы: постепенный рост численности "низов" с доминированием среди них неглубокой бедности, стабильность численности средних слоев на фоне все большей неустойчивости их положения, а также сокращение той части массовых слоев населения, которая является основой для формирования российского среднего класса. Среди других важных последствий снижения ресурсообеспеченности россиян - неизбежный рост среди них депрессивных, агрессивных и протестных настроений.

Ключевые слова: социальная стратификация, социальная структура, ресурсы населения, доходы населения, человеческий капитал, социальный капитал, властный ресурс, благосостояние

Благодарность. Исследование выполнено по гранту РНФ № 17-78-20125-П "Поведенческие стратегии населения в посткризисный период: как новые повседневные реалии жизни россиян скажутся на "коридоре возможностей" развития страны?". in ensuring the well-being of Russians has decreased. All this indicates that the "safety margin" of the country's population has decreased under the influence of a series of economic crises of various nature. Judging by the stability of this trend, it will continue in the future. Taking into account priorities of the social policy of Russia we conclude that for the evolution of the social structure of Russian society this means an intensification of trends that have been traced in recent years: a gradual increase in the share of "lower classes" with the domination of shallow poverty among them; stability of the share of middle strata against the background of increasing instability in their status, and, finally, the decrease of the mass population strata which can be the foundation to develop the middle class in Russia. Among significant impacts of the decline in the resourcefullness of Russians is the inevitable growth of depressive, aggressive and protest moods among them.

Keywords: social stratification, social structure, population resources, population incomes, human capital, social capital, welfare

Acknowledgments. The study was carried out under the grant of the Russian Science Foundation No. 17-78-20125-P "Behavioral strategies of the population in the post-crisis period: How will the new everyday realities of the life of Russians affect the 'corridor of opportunities' for the development of the country?". 
Пандемия коронавируса и последовавший за ней экономический кризис, характеризовавшиеся сокращением доходов населения и усилением проблем с занятостью, резко актуализировали проблему ресурсообеспеченности россиян. С каким «запасом прочности" вступили представители массовых слоев населения страны в очередной экономический кризис и что это означает для будущего социальной структуры России? Ответы на эти вопросы тем более важны, что нынешний экономический кризис - уже третий за последние 12 лет. Как показали наши прошлые исследования, даже до пандемии ситуацию в массовых слоях населения страны можно было охарактеризовать в лучшем случае как "негативную стабилизацию" [Тихонова, 2019]. Стабилизацией ее можно было назвать, так как падение доходов после кризиса 2014-2016 гг. у россиян уже прекратилось, а материальное положение, по крайней мере субъективно, у большинства из них перестало ухудшаться. Однако это была негативная стабилизация, так как их материальное положение, ухудшившись за прошедший с 2014 г. период, стабилизировалось к 2019 г. на более низком, чем ранее, уровне.

Объектом нашего исследования выступали представители массовых слоев населения страны, его предметом стала их обеспеченность ключевыми видами ресурсов (экономическим, квалификационным, властным и социальным ${ }^{1}$ ), а главными исследовательскими вопросами стали вопросы о состоянии ресурсообеспеченности россиян к началу пандемии, ее динамике с лета 2008 г., открывшего череду следующих друг за другом кризисов, а также последствиях этих изменений для социальной структуры российского общества.

Теоретико-методологической базой исследования выступал так называемый ресурсный подход к стратификации [Grusky, 2001; Sørensen, 2000; Авраамова, 2018; Бурдье, 2002; Кастельс, 2000; Радаев, 2003; Тихонова, 2006 и др.], предполагающий, что определенные виды ресурсов прямо влияют на место человека в системе общественных отношений, его жизненные возможности и мироощущение. Список таких ресурсов в литературе постепенно расширяется за счет тех из них, которые раньше не рассматривались как детерминанты места в стратификационной иерархии (например, когнитивные и некогнитивные особенности человека), однако в современном обществе начинают играть все более значимую роль.

В целом список ресурсов, значимых для успешности индивидов в социуме вообще и для определения их структурных позиций в частности, приобрел к настоящему времени в ходе как теоретического, так и эмпирического анализа данной проблемы многими зарубежными и отечественными учеными следующий вид:

- экономический ресурс во всех его традиционных видах (деньги, бизнес и т. д.);

- квалификационный ресурс, включая образование и навыки, то есть человеческий капитал ${ }^{2}$;

- социальный ресурс (включенность в сети социальных связей разного качества);

\footnotetext{
1 Особая роль именно этих видов ресурсов в формировании определенного уровня благосостояния населения и их влияние на место россиян в социальной структуре общества были подробно обоснованы в [Тихонова, 2014].

2 Понятие «человеческий капитал" используется в данном случае в его трактовке Г. Беккером [Becker, 1964].
} 
- властный ресурс в различных его видах (политический, административный и т. п.);

- символический ресурс, связанный с престижностью тех или иных характеристик положения и поведения индивидов в сообществе;

- физиологический ресурс (здоровье, трудоспособность и т. п.);

- культурный ресурс, выступающий результатом социализации в определенных условиях;

- личностный ресурс (горизонт планирования, инициативность, ответственность, креативность, исполнительность и т. д.).

Эмпирической базой анализа выступают данные нескольких репрезентативных общероссийских исследований Института социологии ФНИСЦ РАН за период 2008-2020 гг. В их числе исследования: “Малообеспеченные в современной России: кто они? Как живут? К чему стремятся?» (март 2008 г., выборка 1750 человек), “Бедность и бедные в современной России" (апрель 2013 г., выборка 1600 человек), а также восьмая (март - апрель 2018 г., выборка 4000 человек) и десятая (сентябрь 2020 г., выборка 2000 человек) волны Мониторинга Института социологии ФНИСЦ РАН. Модель выборки во всех этих исследованиях была одинаковой: в рамках каждого территориально-экономического района с учетом соответствующих данных статистики задавались квоты по типам поселений, полу, возрасту и социально-профессиональной принадлежности. Во всех случаях интервью проходили при личном контакте с респондентом.

\section{Основные результаты исследования}

Обеспеченность россиян экономическим ресурсом осенью 2020 г. была довольно низкой. Собственный среднемесячный доход на этот момент составлял всего 27542 руб. (и 32522 руб. у работающих). При этом он был сильно дифференцирован по разным типам поселений, составляя в среднем 40822 руб. в Москве и Санкт-Петербурге, 28596 руб. в центрах субъектов РФ, 24921 руб. в райцентрах и 22001 руб. в селах. Еще более глубока (от 33005 руб. в Москве и Санкт-Петербурге до 16242 руб. в селах) была дифференциация среднедушевых доходов в домохозяйствах респондентов из разных типов поселений. Это побудило нас использовать для анализа связанных с доходом проблем как абсолютные его показатели, так и показатель отношения соответствующего вида доходов к его поселенческой медиане.

Натуральные поступления от подсобного хозяйства входили в число основных источников доходов лишь у каждого пятого россиянина, причем роль этого источника доходов также была сильно дифференцирована по типам поселений (см. табл. 1).

Как видно из таблицы 1, для городских жителей, особенно в Москве и СанктПетербурге, характерна бо́льшая распространенность доходов от занятости по найму, а для жителей сел - трансферты и подсобное хозяйство. Однако более широкая распространенность подсобного хозяйства не может скомпенсировать характерный для сел более низкий уровень денежных доходов, поскольку доходы от него входят в число основных видов доходов лишь у трети сельских жителей. При этом подсобное хозяйство начинает использоваться активнее в условиях 
экономических кризисов в любых типах поселений. Так, в условиях последнего кризиса доля рассматривающих его как один из основных источников доходов выросла даже в столицах: в 2018 г. подсобное хозяйство называли в числе основных источников доходов семьи 2,3\% москвичей и петербуржцев при 6,3\% в 2020 г., а в целом по стране-13,3\% при 20,3\% в 2020 г. Таким образом, население страны ответило на кризис способом, традиционно выручавшим его в кризисные периоды на протяжении многих десятилетий - ростом активности на приусадебных, садовых, дачных и т.д. участках. Однако у большинства россиян такая возможность отсутствует - лишь 40,0 \% из них имеют землю в собственности в любой из этих форм.

Таблица 1. Основные источники доходов домохозяйств из разных типов поселений, 2020 г., \%*

\begin{tabular}{|c|c|c|c|c|c|}
\hline Источники доходов & $\begin{array}{c}\text { Москва } \\
\text { и СПб. }\end{array}$ & $\begin{array}{c}\text { Центры } \\
\text { субъектов } \\
\text { РФ }\end{array}$ & Райцентры & Села & $\begin{array}{l}\text { По массиву } \\
\text { в целом }\end{array}$ \\
\hline \multicolumn{6}{|l|}{ Доходы от занятости по найму } \\
\hline $\begin{array}{l}\text { Заработная плата по основному } \\
\text { месту работы }\end{array}$ & 69,4 & 68,9 & 65,7 & 60,5 & 65,9 \\
\hline Разовые или временные приработки & 23,8 & 15,1 & 15,9 & 17,3 & 16,8 \\
\hline Совместительство & 11,5 & 5,3 & 5,5 & 3,8 & 5,8 \\
\hline \multicolumn{6}{|l|}{ Доходы от занятости не по найму** } \\
\hline $\begin{array}{l}\text { Подсобное хозяйство (на даче или } \\
\text { приусадебном участке) }\end{array}$ & 6,3 & 14,9 & 16,7 & 35,5 & 20,3 \\
\hline Собственный бизнес & 2,0 & 4,2 & 1,9 & 2,6 & 2,8 \\
\hline \multicolumn{6}{|l|}{ Доходы от имеющихся активов } \\
\hline $\begin{array}{l}\text { Доходы от собственности, в т.ч. } \\
\text { от сдачи в аренду имущества, про- } \\
\text { центы по вкладам и т. п. }\end{array}$ & 5,6 & 4,8 & 4,0 & 3,9 & 4,4 \\
\hline \multicolumn{6}{|l|}{ Трансферты } \\
\hline $\begin{array}{l}\text { Пенсии, пособия и т. п. выплаты } \\
\text { от государства }\end{array}$ & 34,1 & 38,4 & 38,1 & 48,1 & 40,0 \\
\hline $\begin{array}{l}\text { Помощь, получаемая от родственни- } \\
\text { ков, друзей, соседей и т. п. }\end{array}$ & 6,7 & 11,2 & 11,2 & 13,5 & 11,4 \\
\hline
\end{tabular}

* В таблице приведены только те источники доходов, которые сами респонденты относили к числу основных. Это означает, что они могли получать и доходы иных видов, но те не оказывали значимого влияния на их финансовое положение. Светлым фоном выделены показатели, превышающие средние по массиву более чем на $3 \%$, а темным фоном - меньше средних по массиву на ту же величину.

** И доходы от подсобного хозяйства, и доходы от собственного бизнеса обычно для представителей массовых слоев населения являются доходами от самозанятости, а не классической предпринимательской деятельности. С другой стороны, они отличаются по ряду сущностных признаков от занятости по найму, поэтому мы выделили их в таблице в особую группу.

Если же говорить не о текущих возможностях, а о накопленных в различных формах прошлых доходах, то есть о способной приносить доход собственности (бизнес, вклады, имущество, которое можно было бы продать или сдать в аренду и т. п.), то и с ними у большинства россиян ситуация довольно сложная. Приносящие ренту активы в числе основных доходов домохозяйств можно встретить у очень 
незначительной части массовых слоев - максимум у $7 \%$ их представителей. При этом около половины населения не имеет в собственности, помимо занимаемого жилья, вообще никакой недвижимости. В крупных городах, где любая недвижимость относительно дороже, таких еще больше - около $60 \%$. Чаще же всего (58,2\%) обладателей какой-либо недвижимости, помимо занимаемого жилья, можно встретить в селах, где в подавляющем большинстве случаев эта недвижимость - просто приусадебный участок. Поскольку его стоимость, как правило, невелика и он играет значимую роль в обеспечении семьи продуктами питания, то его продажа (в большинстве случаев к тому же и объективно невозможная) скорее ухудшит, чем улучшит положение домохозяйства. Соответственно, имеющуюся у представителей массовых слоев населения недвижимость, помимо занимаемого жилья, в большинстве случаев нельзя рассматривать как реальный экономический ресурс, конвертируемый в денежную форму.

Что же касается сбережений, то их даже в относительно благополучное время обычно имели около трети россиян. Последний же кризис, сильно ударивший по возможностям их занятости и доходам, привел к активному использованию этих сбережений: 15,2\% опрошенных представителей массовых слоев населения сказали осенью 2020 г., что им уже пришлось потратить бо́льшую часть сбережений (или даже все) в связи с кризисом. Неудивительно в этих условиях, что общее число имеющих сбережения россиян сократилось и они остались всего у $27,7 \%$. Особенно резко (почти на четверть в относительном выражении) уменьшилась доля имеющих крупные сбережения, позволяющие прожить на них не менее года (см. рис. 1).

Рис. 1. Динамика наличия сбережений среди представителей массовых слоев населения за 2008-2020 гг., \%

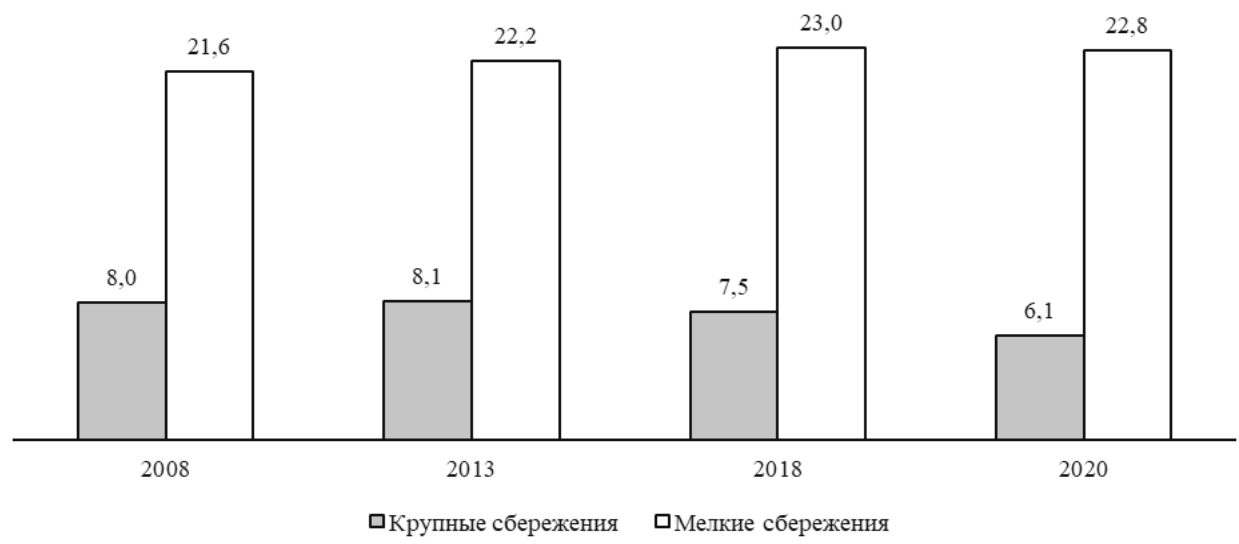

Сильнее всего тенденция сокращения числа имеющих сбережения проявилась в Москве и Санкт-Петербурге, по которым наиболее болезненно ударили ограничения деловой активности, введенные под влиянием пандемии (см. рис. 2). Неслучайно именно в них максимальным (16,3\%) было число тех, кто отмечал, что за время кризиса им пришлось активно использовать свои сбережения. 
Рис. 2. Динамика наличия сбережений среди жителей разных типов поселений, 2018-2020 гг., \%

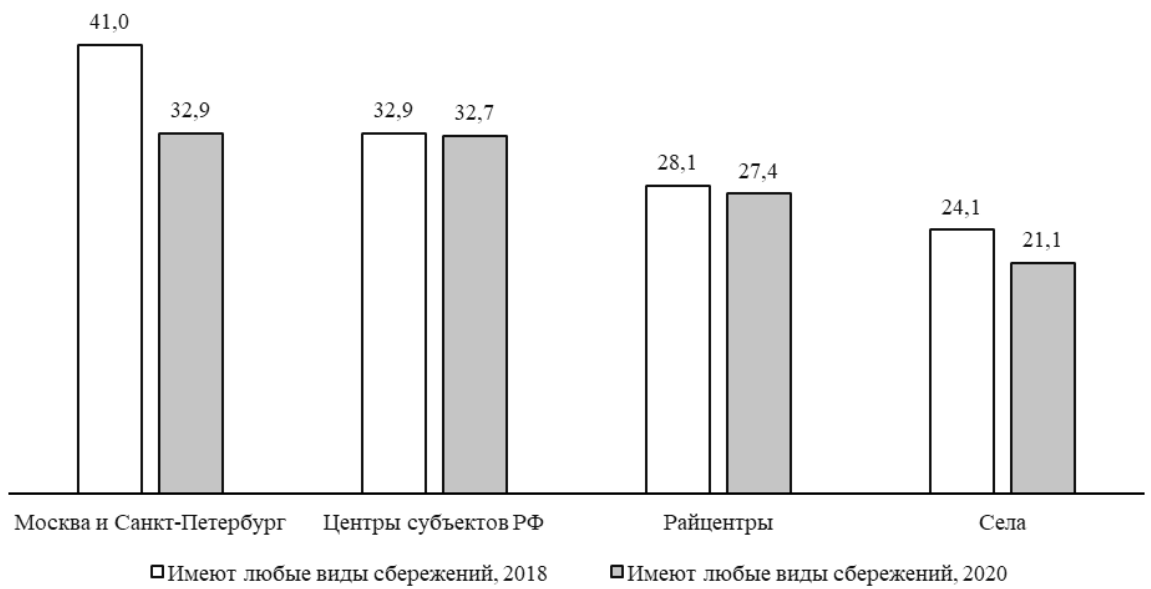

Таким образом, с точки зрения сокращения финансовой «подушки безопасности" россияне уже в первые месяцы пандемии пострадали довольно сильно. Об этом же говорят и данные других источников, согласно которым только в ходе первой волны пандемии коронавируса работающие россияне недосчитались 841 млрд руб. доходов, причем именно Москва и Санкт-Петербург понесли наибольшие потери - фонд оплаты труда в них снизился на 243 млрд и 69,8 млрд руб. соответственно ${ }^{3}$.

На фоне сокращения текущих доходов многие из тех, кто не смог использовать для компенсации этого сокращения отсутствующие сбережения, вынуждены были формировать или увеличивать долговую нагрузку. В сентябре 2020 г. доля имеющих те или иные виды кредитно-долговой нагрузки составляла $44,5 \%$, хотя в 2018 г. ее имели 41,7\%, а весной 2008 г.- всего 26,3\% представителей массовых слоев населения. При этом структура этой нагрузки видоизменилась (см. рис. 3) - выросло число имеющих те ее виды, которые характерны сейчас в России прежде всего для наименее обеспеченных россиян [Тихонов, 2019], то есть накопившиеся мелкие долги и долги по оплате коммунальных услуг и квартплаты. Одновременно слегка сократилось число имеющих банковские кредиты, что объясняется частичным уходом заемщиков из-за сложностей получения кредитов в банках в микрофинансовые организации ${ }^{4}$, условия выплаты кредитов в которых относительно тяжелее.

\footnotetext{
з Эксперты оценили потери россиян в пандемию в 16 млн средних зарплат // РБК. 2020. 16 октября. URL: https:// www.rbc.ru/economics/16/10/2020/5f885dac9a79473eb1819daf (дата обращения: 08.08.2021).

4 Анализ динамики долговой нагрузки населения России в IV квартале 2019 - I квартале 2020 года на основе данных бюро кредитных историй. Информационно-аналитический материал. М.: Банк России, 2020. C. 2. URL: http:// www.cbr.ru/collection/collection/file/31946/inf-material_bki_2020q1.pdf (дата обращения: 08.08.2021).
} 


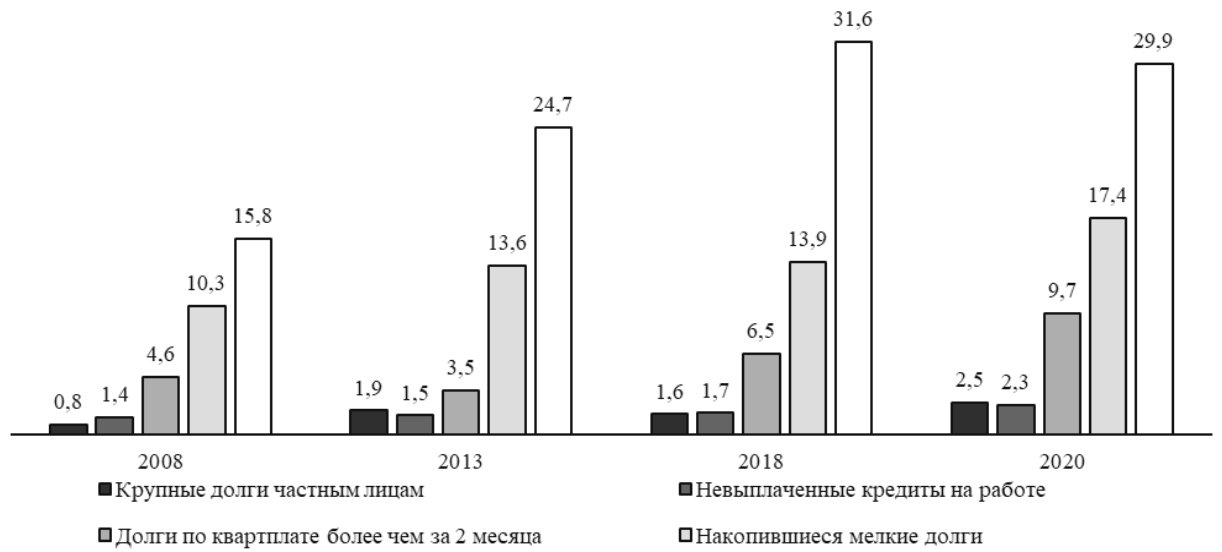

口Кредиты банкам

Что же касается квалификационного ресурса, то обеспеченность им россиян, напротив, увеличивается. Это связано с длящимся уже много лет ростом в России числа лиц, получивших высшее образование. К 2019 г. их доля достигла 34,2\% всех занятых (в возрастной группе 25-29 лет-41,1\%) ${ }^{5}$.

Однако роль этого ресурса для благополучия многих россиян снизилась. Если в 2008 г. средний собственный доход лиц с высшим образованием превышал аналогичный доход лиц без него в 1,48 раза, то к 2020 г. этот разрыв сократился до 1,39. В основном эта тенденция связана с ухудшением положения пенсионеров с высшим образованием и ростом безработицы среди россиян трудоспособного возраста, имеющих высшее образование ${ }^{6}$, поскольку и в 2008 г., и в 2020 г. индивидуальный доход работающих россиян с высшим образованием превышал доход лиц с более низким образовательным уровнем в среднем в 1,38 раза. В то же время, учитывая, что ренты на высшее образование в 2010-х годах сохранялись в основном у представителей тех профессиональных групп, для которых оно не требуется, такая ситуация говорит о сохранении уже фиксировавшейся по отношению к концу 2000-х [Лукьянова, 2010] и середине 2010-х годов рядом отечественных исследователей [Модель, 2018; Тихонова, Каравай, 2018] тенденции роста уравнительности в доходах населения страны. Снижение роли высшего образования при определении размеров заработной платы связано с нарастающим дисбалансом между числом лиц с высшим образованием и численностью рабочих мест, предполагающих этот образовательный уровень, то есть несоответствием спроса

\footnotetext{
5 Труд и занятость в России. 2019. Росстат. М., 2019. С. 25.

6 Доля безработных с высшим образованием в составе безработного населения страны выросла с 12,3\% в 2008 г. См.: Экономическая активность населения России (по результатам выборочных обследований). 2010. Росстат. C. 135. URL: https://rosstat.gov.ru/bgd/regl/B10_61/Main.htm (дата обращения: 08.08.2021), а также: Рабочая сила, занятость и безработица в России - 2020 г. ФСГС РФ. Табл. 5.6. URL: https://rosstat.gov.ru/bgd/regl/B20_61/Main. htm (дата обращения: 08.08.2021).
} 
и предложения на соответствующий тип рабочей силы на рынке труда. Так, при доле лиц с высшим образованием в 34,2\% всех занятых численность специалистов высшей квалификации составляла в 2018 г. лишь 24,6\% всех занятых ${ }^{7}$.

Что же касается властного ресурса, который может существовать в различных формах - политического ресурса, административного ресурса, ресурса влияния на принятие решений у себя на работе, автономности труда и т.д., то мы, в силу особенностей использованной эмпирической базы, анализировали только две из них: административный ресурс и ресурс влияния. Административный ресурс напрямую связан с профессиональным статусом, поэтому как имеющих его мы рассматривали руководителей разного уровня, а также предпринимателей, руководящих наемными работниками. Таких в нашей выборке 2020 г. среди работающих россиян было 6,9\%. Властный ресурс в форме ресурса влияния был распространен среди работающих россиян заметно шире, но характеризовал лишь около трети работающих. При этом даже наличие руководящей должности не гарантирует сегодня в России возможности влиять на происходящее у себя на работе - почти 30 \% руководителей не имеют этого влияния. Это означает, что они являются скорее "надсмотрщиками", выполняющими функции контроля за трудом других [Wright, 1997], чем лицами, принимающими решения. В целом почти две трети работающих россиян (62,1\%) осенью 2020 г. были полностью лишены властного ресурса в его административной форме и/или в форме ресурса влияния. В обеих этих формах властный ресурс имели лишь 3,8\% работающих.

Наличие властного ресурса важно, поскольку, как было показано в литературе, в стабильных экономических условиях этот ресурс дает в современном российском обществе ощутимый экономический эффект, снижает отчуждение в труде и обеспечивает более высокие статусные позиции [Тихонова, 2014; Коленникова, 2017]. Эту тенденцию подтверждают и наши последние данные. В сентябре 2020 г. среди профессионалов зарплату выше двух медианных зарплат в их типах поселений имеющие ресурс влияния у себя на работе получали в полтора раза чаще, чем не имеющие его (35,6\% против $24,4 \%)$. Кроме того, этот ресурс даже в условиях пандемии позволял человеку сохранять более позитивное восприятие своего материального положения и своей жизни в целом - по всем этим позициям доля оценивших ситуацию с этими сторонами своей жизни как хорошую была у имеющих властный ресурс примерно в полтора раза выше, чем у не имеющих его. При этом объективно влияние этого ресурса на позиции человека на рынке труда и в целом в социально-экономических отношениях заметно меньше. Например, среди профессионалов, имеющих и не имеющих властный ресурс, доли тех, чье материальное положение в кризис улучшилось, составляли, соответственно, 16,7\% и 12,3\%, а тех, у кого оно ухудшилось,- 33,5\% и 37,6\%. Как видим, различия невелики, хотя и статистически значимы.

Учитывая роль властного ресурса для субъективного и объективного благополучия человека, существенно, что с 2008 г. по осень 2020 г. показатели обладателей этого ресурса среди работающих россиян уменьшились. Произошло это прежде всего за счет сокращения числа имеющих ресурс влияния - их доля

\footnotetext{
Труд и занятость в России. 2019. Росстат. М., 2019. С. 32.
} 
упала в относительном выражении на 8,5\% (в 2008 г. она составляла 39,5\% при $36,4 \%$ в 2020 г.).

Для общего субъективного благополучия человека и устойчивости его положения, особенно в кризис, важно также качество его социального капитала ${ }^{8}$. Помощь, получаемая от родственников, друзей, соседей и т. п., осенью 2020 г. была значимым источником доходов 11,4\% российских семей, и доля эта за период с весны 2008 г. выросла вдвое - тогда она составляла всего 5,8\%.

Однако если рассмотреть этот ресурс в его потенциальной форме, учитывая при этом также другие его значимые аспекты, то становится понятно, что у представителей массовых слоев российского общества этот ресурс скорее сокращается, чем растет. И решающий вклад в его сокращение внесли трудности середины и конца 2010-х годов (см. табл. 2). Наиболее тревожен значительный рост числа россиян, вообще не имеющих социального ресурса: с 2008 г. по 2020 г. их численность выросла практически в полтора раза и стала составлять около половины всех представителей массовых слоев. Особенно сложная ситуация с ним складывается в селах, где, в силу особенностей их инфраструктуры и относительно низкого уровня жизни, окружение человека, даже при желании, зачастую не в состоянии оказать ему необходимой поддержки. 59,6\% жителей сел осенью 2020 г. вообще не имели социального ресурса ни в какой форме (при 31,7 \% в столицах и 40,6\% в центрах субъектов РФ), а у остальных доминировали такие его формы, как возможность взять в долг небольшую сумму денег $(19,5 \%)$ и поиск приработков $(13,2 \%)$.

Таблица 2. Специфика ресурса социальных сетей россиян, ИС ФНИСЦ РАН, 2008-2020 гг., \% (отранжировано по способности сетей оказать помощь соответствующего вида в 2020 г.)

\begin{tabular}{|l|c|c|c|}
\hline \multicolumn{1}{|c|}{ Виды помощи, которые могут оказать социальные сети } & \multicolumn{3}{|c|}{ Годы } \\
\cline { 2 - 4 } & $\mathbf{2 0 0 8}$ & $\mathbf{2 0 1 3}$ & $\mathbf{2 0 2 0}$ \\
\hline Возможность взять в долг довольно крупную сумму* & 36,2 & 34,8 & 34,0 \\
\hline Поиск приработков & $-* *$ & $-* *$ & 20,4 \\
\hline Обращение к хорошим врачам или устройство в хорошую больницу & 25,1 & 24,4 & 18,2 \\
\hline Устройство на хорошую работу & 17,6 & 14,5 & 12,3 \\
\hline Устройство детей в хорошую школу & 8,2 & 6,8 & 7,7 \\
\hline Решение жилищной проблемы & 4,5 & 6,9 & 6,8 \\
\hline $\begin{array}{l}\text { Содействие в доступе к должностным лицам, способным помочь в ре- } \\
\text { шении их проблем }\end{array}$ & $-* *$ & $-* *$ & 5,8 \\
\hline Поступление в хороший вуз & 5,7 & 6,1 & 4,3 \\
\hline Продвижение по карьерной лестнице & 4,5 & 3,8 & 3,6 \\
\hline Не имеют знакомых, способных оказать такого рода помощь & 32,3 & 34,4 & 46,2 \\
\hline
\end{tabular}

* В опросе 2020 г. эта позиция подразделялась на две, характеризующие возможность взять в долг до 100 тыс. руб. и более 100 тыс. руб. Соответствующие показатели составили в 2020 г. 27,8\% и 6,2\%.

** В опросах 2008 и 2013 г. эта позиция отсутствовала.

\footnotetext{
8 В соответствии с определением П. Бурдье, социальный капитал - это "совокупность реальных или потенциальных ресурсов, связанных с обладанием устойчивой сетью более или менее институционализированных отношений взаимного знакомства и признания - иными словами, с членством в группе" [Бурдье, 2002: 66].
} 
Если, учитывая такие ключевые для определения жизненных шансов человека виды ресурсов, как экономический, квалификационный, властный и социальный, посмотреть на общую ресурсообеспеченность россиян ${ }^{9}$, разделив их по этому показателю на группы, то большинство населения страны оказывается в составе безресурсной и низкоресурсной групп. Чаще всего представители безресурсной группы проживают в селах (38,4\%). Что же касается низкоресурсной группы, то это относительно чаще $(30,7$ \%) жители районных центров; причем те, кто все-таки имеет какой-то вид ресурсов, обычно (в 57,9\% случаев) обладают социальным ресурсом либо в форме возможности взять в долг менее 100 тыс. руб. (28,9\%), либо в форме помощи в поиске разовых и временных приработков (23,5\%). Все остальные разновидности социального ресурса наблюдаются в данной группе гораздо реже. Таким образом, даже этот ресурс у представителей низкоресурсной группы довольно низкого качества. Для проживающих преимущественно в областных (28,5\%) и районных (28,9\%) центрах представителей среднересурсной группы также характерно наличие прежде всего социального ресурса $(75,9 \%)$. Все остальные виды ресурсов в ней имеет меньшинство. Наконец, в состоящей в основном из жителей столиц $(15,0 \%)$ и центров субъектов РФ $(37,4 \%)$ представителей высокоресурсной группы большинство имеет все виды ресурсов, при этом максимален в ней показатель имеющих социальный, а минимален - показатель имеющих экономический ресурс (см. табл. 3). Однако наиболее характерно для нее не только наличие всех видов ресурсов у большинства ее членов, но и наличие у них властного ресурса, о значимости которого мы уже говорили выше: именно по нему отрыв данной группы от остальных максимален.

Таблица З. Наличие различных ресурсов у россиян из групп с разной ресурсообеспеченностью, 2020 г., \%

\begin{tabular}{|l|c|c|c|c|}
\hline \multirow{2}{*}{$\begin{array}{c}\text { Имеющиеся виды } \\
\text { ресурсов }\end{array}$} & \multicolumn{4}{|c|}{$\begin{array}{c}\text { Группы с разным числом распо- } \\
\text { лагаемых видов ресурсов }\end{array}$} \\
\cline { 2 - 5 } & $\mathbf{0}$ & $\mathbf{1}$ & $\mathbf{2}$ & $\mathbf{3 - 4}$ \\
\hline Экономический & 0 & 18,0 & 40,6 & 66,9 \\
\hline Квалификационный & 0 & 14,7 & 46,4 & 84,7 \\
\hline Властный & 0 & 9,4 & 37,1 & 79,0 \\
\hline Социальный & 0 & 57,9 & 75,9 & 92,1 \\
\hline
\end{tabular}

Примечание. Серым фоном здесь и далее выделены позиции, составляющие более $50 \%$, то есть типичные для данной группы в целом.

Если говорить о динамике численности групп с разной ресурсообеспеченностью, то за период с 2008 г. по 2020 г. заметно выросла доля группы безресурсных россиян, в состав которой переместилась часть более ресурсных групп, сокративших за эти годы свою численность. Особенно резко уменьшилась в составе массовых слоев населения доля высокоресурсной группы (см. рис. 4).

\footnotetext{
9 Индикатором нулевого значения экономического ресурса выступало отсутствие в собственности любых сбережений, квалификационного - отсутствие высшего образования, властного - отсутствие административного ресурса или ресурса влияния в любой его форме, социального - отсутствие среди окружения людей, способных оказать поддержку хотя бы в какой-то из рассматривавшихся форм.
} 


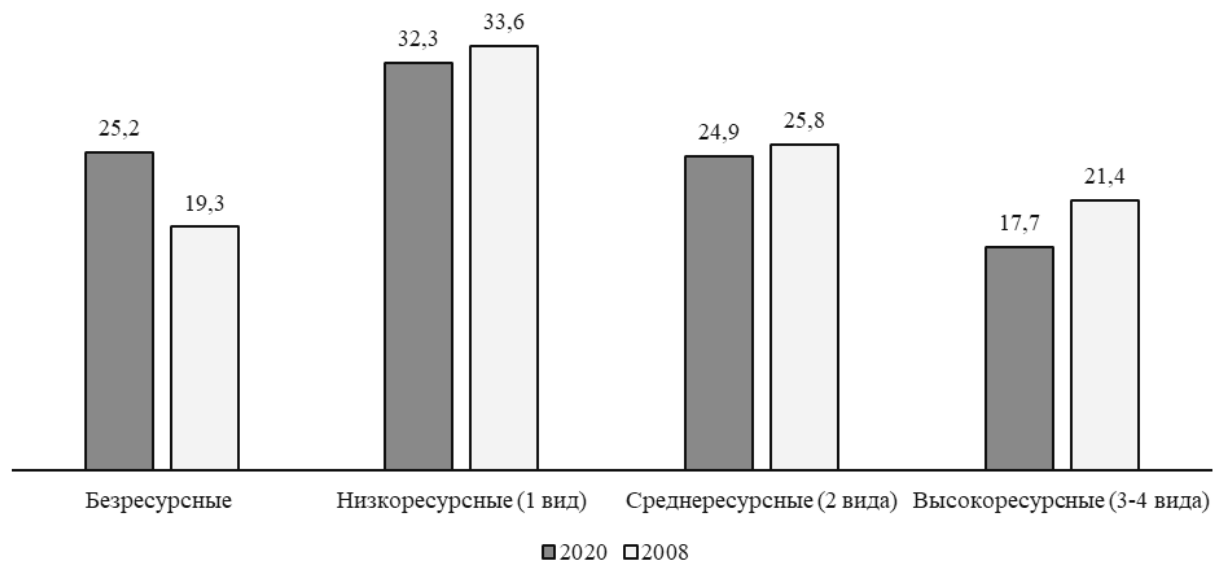

Понимание динамики ресурсообеспеченности россиян, так же как и принадлежности большинства представителей массовых слоев населения к без- и низкоресурсным группам, важно прежде всего потому, что ресурсообеспеченность человека прямо связана не только с его объективным материальным благополучием, но и с его субъективным благополучием, а также с прочностью его положения в кризисных условиях. Так, коэффициент Спирмена составлял в базе 2020 г. для взаимосвязи ресурсообеспеченности человека и его самооценок своего материального положения 0,342; соотношения его индивидуального дохода с поселенческой медианой зарплат-0,305; самооценками собственной жизни -0,253; чувств, с которыми он думает о собственном будущем, - 0,233.

Различия по всем этим сторонам жизни у представителей групп с разной ресурсообеспеченностью были очень существенными (см. табл. 4). Так, среди бези низкоресурсных россиян большинство характеризовалось ухудшением их материального положения за последний год и пессимизмом в отношении собственного будущего, а работающая их часть в массе своей столкнулась на работе с такими негативными последствиями пандемии, как сокращение зарплаты, потеря работы, неоплачиваемый отпуск, задержки зарплаты и т. п. С другой стороны, для среднеи высокоресурсных россиян в большинстве случаев характерны относительно высокие индивидуальные доходы и уверенность в собственном будущем, а для высокодоходной - также тот уровень среднедушевых доходов, который обеспечивает в современной России образ жизни, типичный для среднего класса [Модель оходной стратификации..., 2018].

Учитывая упоминавшийся выше рост числа безресурсных россиян и сокращение численности высокоресурсной их группы в ходе кризисов 2008-2009 гг., 2014-2016 гг. и 2020 г., такая картина особенностей представителей этих групп свидетельствует с точки зрения эволюции социальной структуры российского общества не только об общем ухудшении положения массовых слоев населе- 
ния страны, но и о локализации основной массы негативных последствий этих кризисов в группах с наименьшей ресурсообеспеченностью. С другой стороны, приведенные в таблице 4 данные говорят о подрыве благополучия в ходе этих кризисов, и особенно в ходе последнего кризиса, прежде всего в составляющих базу формирования среднего класса россиян. При этом для без- и низкоресурсных групп характерно большее единообразие оценок и в целом бо́льшая однородность их положения, чем для средне- и высокоресурсных. Однако неуверенность в собственном будущем и страх перед ним, провоцирующие депрессивные настроения, чувство агрессии и готовность к протестам довольно широко распространены и в среднересурсной группе.

Таблица 4. Некоторые аспекты жизни россиян с разной ресурсообеспеченностью, 2020 г., \%*

\begin{tabular}{|c|c|c|c|c|c|}
\hline \multirow[t]{2}{*}{ Аспекты жизни } & \multicolumn{4}{|c|}{$\begin{array}{c}\text { Группы с разным числом } \\
\text { располагаемых видов } \\
\text { ресурсов }\end{array}$} & \multirow[t]{2}{*}{$\begin{array}{c}\text { По } \\
\text { массиву } \\
\text { в целом }\end{array}$} \\
\hline & 0 & 1 & 2 & $3-4$ & \\
\hline \multicolumn{6}{|l|}{ Объективные аспекты жизни } \\
\hline \multicolumn{6}{|l|}{$\begin{array}{l}\text { Соотношение индивидуального дохода с поселенческой } \\
\text { медианой зарплат, в т. ч.: }\end{array}$} \\
\hline — не более 0,75 поселенческой медианы & 26,6 & 21,0 & 12,8 & 6,0 & 17,8 \\
\hline - более 1,25 поселенческой медианы & 36,5 & 42,5 & 54,4 & 73,6 & 49,3 \\
\hline \multicolumn{6}{|l|}{$\begin{array}{l}\text { Соотношение среднедушевых доходов в домохозяйстве } \\
\text { с их поселенческой медианой, в т. ч.: }\end{array}$} \\
\hline не более 0,75 поселенческой медианы & 43,5 & 35,7 & 22,7 & 13,5 & 30,6 \\
\hline более 1,25 поселенческой медианы & 16,1 & 21,1 & 33,9 & 50,9 & 28,2 \\
\hline \multicolumn{6}{|l|}{ Динамика материального положения за последний год: } \\
\hline - ухудшилось & 57,8 & 50,1 & 40,6 & 34,0 & 46,9 \\
\hline - улучшилось & 3,4 & 7,4 & 10,8 & 17,6 & 9,1 \\
\hline $\begin{array}{l}\text { Испытали негативные последствия кризиса (сокращение } \\
\text { зарплаты, потеря работы, неоплачиваемый отпуск, за- } \\
\text { держки зарплаты и т. п.)** }\end{array}$ & 60,0 & 55,1 & 47,7 & 37,8 & 50,2 \\
\hline \multicolumn{6}{|l|}{ Субъективные самооценки различных аспектов своей жизни } \\
\hline \multicolumn{6}{|l|}{\begin{tabular}{|l|l} 
Самооценки материального положения: & \\
\end{tabular}} \\
\hline - хорошо & 2,6 & 6,3 & 12,7 & 24,9 & 10,3 \\
\hline - плохо & 47,1 & 29,1 & 18,1 & 11,0 & 27,7 \\
\hline \multicolumn{6}{|l|}{ Самооценки собственной жизни: } \\
\hline - хорошо & 8,5 & 21,5 & 26,5 & 39,4 & 22,7 \\
\hline - плохо & 16,3 & 8,2 & 6,6 & 5,9 & 9,5 \\
\hline \multicolumn{6}{|l|}{ Видение личного будущего, В т. ч. } \\
\hline - уверены в том, что оно будет благоприятным & 20,1 & 34,5 & 39,7 & 56,0 & 36,1 \\
\hline - не уверены в этом & 65,0 & 49,4 & 43,6 & 33,1 & 49,0 \\
\hline $\begin{array}{l}\text { Думают о собственном будущем с беспокойством, стра- } \\
\text { хом, отчаянием }\end{array}$ & 56,0 & 42,6 & 39,3 & 27,4 & 42,5 \\
\hline
\end{tabular}

* В таблице приведены полярные ответы. Ответы типа “удовлетворительно», "осталось тем же» и т. п., а также затруднившиеся с ответом в таблице не указаны.

**Данные приведены по работающим. 


\section{Выводы}

Анализ ресурсообеспеченности массовых слоев населения России свидетельствует о том, что четверть их представителей не обладает никакими из ключевых ресурсов, способных облегчить их положение или упростить для них адаптацию в условиях экономических кризисов. Еще около трети входят в состав низкоресурсной группы, имеющей только один из таких видов ресурсов, как экономический, квалификационный, властный и социальный. Численность высокоресурсной группы, имеющей минимум три из этих четырех ключевых ресурсов, составляет менее $20 \%$ населения страны.

Ресурсообеспеченность россиян постепенно уменьшается. С августа 2008 г. до сентября 2020 г. доля не имеющих ни одного из этих четырех ключевых видов ресурсов выросла в относительном выражении на 30,6 \% (с 19,3\% до 25,2\%), а доля высокоресурсной группы в составе населения сократилась на 20,9\% (с 21,4\% до 17,7\%). Подобная динамика тем более парадоксальна, что численность имеющих такой, казалось бы, ключевой для современной экономики вид ресурсов, как квалификационный, за этот период значительно выросла. Однако, поскольку число рабочих мест для лиц с высшим образованием за это время увеличилось в меньшей степени, чем их численность, то дисбаланс спроса и предложения на соответствующем сегменте рынка труда привел к падению отдач на этот вид ресурсов - по крайней мере, на тех рабочих местах, где предполагается соответствующий уровень образования. В результате текущие доходы россиян с высшим образованием за период 2008-2020 гг. относительно уменьшились.

Что же касается экономического ресурса, то какие-либо сбережения имели в сентябре 2020 г. лишь 27,7\% представителей массовых слоев. Это меньше, чем перед кризисом 2008 г., что говорит о снизившемся под влиянием череды экономических кризисов разной природы "запасе прочности" населения. Об этом же говорит и возросшая кредитно-долговая нагрузка россиян, структура которой за этот период резко ухудшилась, поскольку на фоне относительной стабильности численности имеющих долги частным лицам и организации-работодателю (с которыми обычно легче договориться о рассрочке в случае каких-то жизненных проблем) резко выросла доля имеющих кредиты в банках и микрофинансовых организациях. Увеличилась, особенно за время последнего кризиса, также доля имеющих накопившиеся мелкие долги и долги по квартплате - виды задолженностей, характерные для находящихся в наиболее тяжелом положении домохозяйств. Широкое распространение получила множественная кредитно-долговая нагрузка. В наибольшей степени кредитно-долговая нагрузка, в том числе и множественная, распространена в безресурсной группе, где она характерна для большинства.

Не могут «подстраховать" большинство россиян и второе жилье, дачи, гаражи и т. п. Во-первых, любая недвижимость помимо занимаемого жилья (от места на коллективной стоянке до второго жилья), как и сбережения, у большинства россиян отсутствует, и реже всего она встречается в крупных городах, где ее стоимость и ликвидность, как правило, наиболее высоки. А во-вторых, если говорить о низкоресурсных и безресурсных группах, то любая недвижимость встречается у них гораздо реже, чем у остальных россиян, а если и встречается, то это обычно 
лишь приусадебные участки, поскольку все ликвидное имущество, если оно у них и было, они уже давно продали.

Распространенность властного ресурса среди работающих россиян за период с 2008 г. также сократилась. Произошло это прежде всего за счет уменьшения численности имеющих у себя на работе ресурс влияния на принятие решений. Это означает, что такая специфичная для российской производственной культуры черта, как концентрация всех полномочий только у руководящего административного ядра организации, а не распределение их в соответствии с компетенциями сотрудников, продолжает усугубляться. Данная тенденция, доходящая до отсутствия ресурса влияния на происходящее в зоне их ответственности даже у ряда руководителей (особенно среднего и низшего звена), противоречит глобальному экономическому тренду на максимально широкое распределение полномочий, распространение сетевых структур и т.д. Однако не менее значимы и социальные последствия усиления этой тенденции, поскольку нарастание отчуждения в труде негативно влияет на психологическое самочувствие работников. Кроме того, сокращение численности имеющих властный ресурс в производственных коллективах негативно сказывается на материальном положении работников, поскольку современная экономика предполагает наличие рент на властный ресурс даже в форме ресурса влияния.

Наконец, что касается социального ресурса, то ситуация с ним за период с весны 2008 г. также значительно ухудшилась. Почти у половины россиян нет уже даже этого вида ресурсов, и особенно тяжелая ситуация с ним складывается в селах. Учитывая растущую роль этого ресурса в современной России и общую плохую обеспеченность сельских жителей всеми видами ключевых ресурсов, можно ожидать нарастания разрыва в уровне и качестве их жизни с жителями всех типов городов, особенно - крупных.

Что же касается социальной структуры российского общества, то она будет эволюционировать под влиянием тенденций, прослеживавшихся еще до начала пандемии и усилившихся в ходе последнего кризиса. Продолжится увеличение численности безресурсной группы, при этом за счет наращивания трансфертов от государства в ней сохранится доминирование незначительной глубины их бедности или пребывание чуть выше ее границы. Можно ожидать и усиления ее самовоспроизводства в межгенерационном масштабе. Низко- и среднересурсные группы сохранят свою численность, хотя за счет роста рисков "скатывания" в "низы" положение их представителей будет характеризоваться все большей неустойчивостью. Наконец, являющаяся основой для формирования среднего класса высокоресурсная часть массовых слоев населения продолжит сокращаться. Кроме того, данные нашего анализа свидетельствуют о формировании предпосылок для роста среди россиян депрессивных, агрессивных и протестных настроений, поскольку перспективы динамики их положения, учитывая долгосрочность вектора ухудшения их ресурсообеспеченности, выглядят довольно плачевно.

\section{Список литературы (References)}

Авраамова Е. М. Российское население в постсоветский период: опыт кризисов и социальные ресурсы развития. М. : Издательский дом “Дело" РАНХиГС, 2018. 
Avraamova E. M. (2018) Russian Population in the Post-Soviet Period: Experience of Crises and Social Resources of Development. Moscow: Delo RANEPA. (In Russ.)

Бурдье П. Формы капитала // Экономическая социология. 2002. Т. 3. № 5. C. $60-74$.

Bourdieu P. (2002) Forms of Capital. Economic Sociology. Vol. 3. No. 5. P. 60-74 (In Russ.)

Кастельс М. Информационная эпоха: экономика, общество и культура. М.: ГУ ВШЭ, 2000.

Castells M. (2000) The Information Age: Economy, Society and Culture. M.: SU HSE. (In Russ.).

Коленникова Н.Д. Особенности властного статуса занятого населения современной России // Мониторинг общественного мнения: экономические исоциальные перемены. 2017. №5. C.214-232. https://doi.org/10.14515/monitoring.2017.5.12. Kolennikova N. D. (2017) Characteristics of the Power Status of Employed Population in Modern Russia. Monitoring of Public Opinion: Economic and Social Changes. No. 5. P. 214-232. https://doi.org/10.14515/monitoring.2017.5.12. (In Russ.)

Лукьянова А. Л. Отдача от образования: что показывает мета-анализ // Экономический журнал Высшей школы экономики. 2010. Т. 14. № 3. С. 326-348. Lukyanova A. L. (2010) Return on Education: What the Meta-Analysis Shows. Economic Journal of the Higher School of Economics. Vol. 14. No. 3. P. 326-348. (In Russ.)

Модель доходной стратификации российского общества: динамика, факторы, межстрановые сравнения / под общ. ред. Н.Е. Тихоновой. М., СПб.:Нестор-История, 2018. Tikhonova N.E. (ed.) (2018) Model of Income Stratification of Russian Society: Dynamics, Factors, Cross-Country Comparisons. Moscow, St. Petersburg: Nestor-Istoriya. (In Russ.)

Радаев В.В. Понятие капитала, формы капиталов и их конвертация / / Общественные науки и современность. 2003. № 2. С. 5-16.

Radaev V.V. (2003) The Concept of Capital, Forms of Capital and Their Conversion. Social Sciences and Modernity. No. 2. P. 5-16 (In Russ.)

Тихонов А. А. Влияние изменений в системе неравенств на особенности финансового поведения россиян в 2003-2018 гг. // Будущее социологического знания и вызовы социальных трансформаций / Отв. ред. М. К. Горшков. М. : ФНИСЦ РАН, 2019. C. 416-419. https://doi.org/10.19181/yadov_conf.2019.

Tikhonov A. A. (2019) Impact of Changes in the System of Inequalities on the Characteristics of the Financial Behavior of Russians in 2003-2018. In: Gorshkov M. K. (ed.) The Future of Sociological Knowledge and the Challenges of Social Transformations. Moscow: FCTAS RAS. P. 416-419. https://doi.org/10.19181/yadov_conf.2019. (In Russ.)

Тихонова Н. Е. Ресурсный подход как новая теоретическая парадигма встратификационных исследованиях // Социологические исследования. 2006. №9. С. 28-39. Tikhonova N.E. (2006) Resource Approach as a New Theoretical Paradigm in Stratification Research. Sociological Studies. No. 9. P. 28-39 (In Russ.) 
Тихонова Н. Е. Социальная структура России: теории и реальность. М. : Новый хронограф, 2014.

Tikhonova N.E. (2014) Social Structure of Russia: Theory and Reality. Moscow: New Chronograph. (In Russ.)

Тихонова Н.Е., Каравай А. В. Динамика некоторых показателей общего человеческого капитала россиян в 2010-2015 гг. // Социологические исследования. 2018. № 5. C. 84-98. https://doi.org/10.7868/S0132162518050082.

Tikhonova N. E., Karavay A. V. (2018) Dynamics of some indicators of Russians' general human capital in 2010-2015. Sociological Studies. No. 5. P. 84-98. https://doi. org/10.7868/S0132162518050082. (In Russ.)

Тихонова Н.Е. "Негативная стабилизация" ифакторы динамики благосостояния населения впосткризисной России // Социологический журнал. 2019. Т. 25 . № 1. C. 27-47. https://doi.org/10.19181/socjour.2018.25.1.6278.

Tikhonova N.E. (2019) "Negative Stabilization" and Factors of the Population Welfare Dynamics in Post-Crisis Russia. Sociological Journal. Vol. 25. No. 1. P. 27-47. https:// doi.org/10.19181/socjour.2018.25.1.6278. (In Russ.)

Becker G.S. (1964) Human Capital: A Theoretical and Empirical Analysis with Special Reference to Education. Chicago: University of Chicago Press.

Grusky D. B. (2001) The Past, Present, and Future of Social Inequality. In: Social Stratification: Class, Race, and Gender in Sociological Perspective. $2^{\text {nd }}$ ed. Boulder: Westview Press. P. 1-51.

Sørensen A. B. (2000) Toward a Sounder Basis for Class Analysis. American Journal of Sociology. Vol. 105. No. 6. P. 1523-1558.

Wright E. O. (1997) Class Counts: Comparative Studies in Class Analysis. Cambridge Cambridge University Press. 